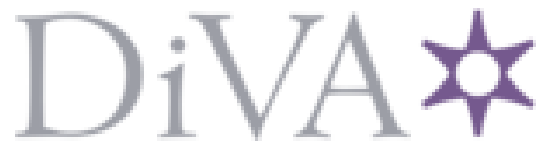

http://www.diva-portal.org

This is the published version of a paper published in .

Citation for the original published paper (version of record):

Kohler, T A., Buckland, P I., Kintigh, K W., Bocinsky, R K., Brin, A. et al. (2018) Paleodata for and from archaeology

PAGES Magazine, 26(2): 68-69

https://doi.org/10.22498/pages.26.2.68

Access to the published version may require subscription.

N.B. When citing this work, cite the original published paper.

Permanent link to this version:

http://urn.kb.se/resolve?urn=urn:nbn:se:umu:diva-158324 


\section{Paleodata for and from archaeology}

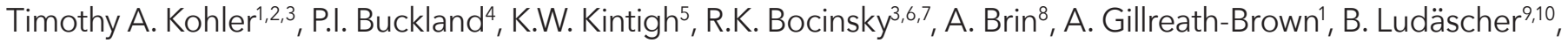
T.M. McPhillips', R. Opitz ${ }^{11}$ and J. Terstriep ${ }^{10}$

\section{Archaeology depends on, and generates, proxy paleoclimatic and paleoenvironmental data. We review various initiatives, most quite recent, by which archaeologists seek to make these data more readily discoverable and useful, to facilitate the cumulation of research.}

Since the birth of the discipline in the mid19th century, archaeologists have recognized that climate variability has a role in explaining the locations, densities, and practices of human populations. The variability archaeologists could then recognize was the large and dramatic sort involving the ebb and flow of glaciations that altered coastlines and changed the areas people could access, and the distributions of plants and animals they depended on (e.g. Lartet 1861; Lubbock 1890).

Along with related advances in the Earth sciences, the development of palynology in the late 19th century, tree-ring dating and dendroclimatology ca. 1930, and radiometric dating in the mid-20th century greatly increased the scope and chronological precision of paleoclimatic proxies. By the mid-20th century, studying fauna, flora, sediments, and other residues from archaeological sites became recognized subdisciplines (e.g. zooarchaeology, paleoethnobotany, geoarchaeology) and standard archaeological practice. Archaeological prospection and excavation increasingly include investigation of bogs, lakes, or packrat middens to assess local environmental change. Today, many of the "grand challenges" facing archaeology involve understanding the range of human responses to climate change and human manipulation of the landscape at various scales (d'Alpoim Guedes et al. 2016; Kintigh et al. 2014).

Barriers to addressing these challenges include lack of access to and understanding of climate-change data relevant to studies of cultural change. Environmental data from archaeological sites yield an anthropocentric view of the past, since they result from human activities including resource harvesting, hunting, and exchange. Activities in and around sites are, however, always subject to external factors; occupants' responses to changes in climate and environment will be reflected as changes in materials excavated from sediments of different ages. Indeed, the ensemble of excavated sites constitutes a "Distributed Observational Network of the Past" (DONOP; Hambrecht et al., in press) that provides the most direct evidence of our long-term interactions with our environments. As the Anthropocene debate has emphasized, human-nature interactions are not recent, simple, one-way, or local. People have been dramatically changing landscapes for over 10,000 years (Smith and Zeder 2013). Any study of paleoclimate, paleoenvironment, or paleobiodiversity, especially using broad-scale aggregated data, must evaluate the potential for human influences on proxy data used to infer natural change or variability (e.g. Li et al. 2014). As our only available line of evidence on past human and social responses to climatic variability, lessons from archaeology are critically important to forming future responses to climatic variability (Jackson et al. 2018). But just as archaeology studies climatic variability, climate change can destroy sites or their contents: we are rapidly losing archaeological data through erosion, rising sea levels, and thawing of permafrost (Hollesen et al. 2018). There is an urgent need for collecting and curating more data before key sediment archives are lost forever.

\section{Major current efforts to curate open archaeological data}

Although archaeologists have been using databases for decades, these were often project-oriented systems with short lifespans. Systematic initiatives to curate archaeological data have appeared in the last two decades, including Digital Antiquity (digitalantiquity.org) and its tDAR database (tdar. org), centered on, but not limited to, US heritage resources; Open Context (opencontext. org) (Wells et al. 2014); and the Archaeology Data Service (archaeologydataservice.ac.uk), the accredited digital repository in the UK for heritage data. Some national data services provide archaeological data, including DANS in the Netherlands (easy.dans.knaw.nl/ui) and the Swedish National Data Service (snd.gu.se/ en). The Ariadne infrastructure (ariadne-infrastructure.eu) is working towards providing a single data-discovery service for all European resources. Although these archives are not specifically oriented towards paleoclimatic data, they contain much data important for understanding past environmental conditions and changes. As their interfaces are rarely designed with this in mind, considerable processing may be required to achieve paleoenvironmental insights. For example, using these data requires coping with the complexities of archaeological stratigraphy and possibly integrating archaeological dating with age-depth modeled reconstructions. Systems for standardized ontological mapping between datasets, such as tDAR's

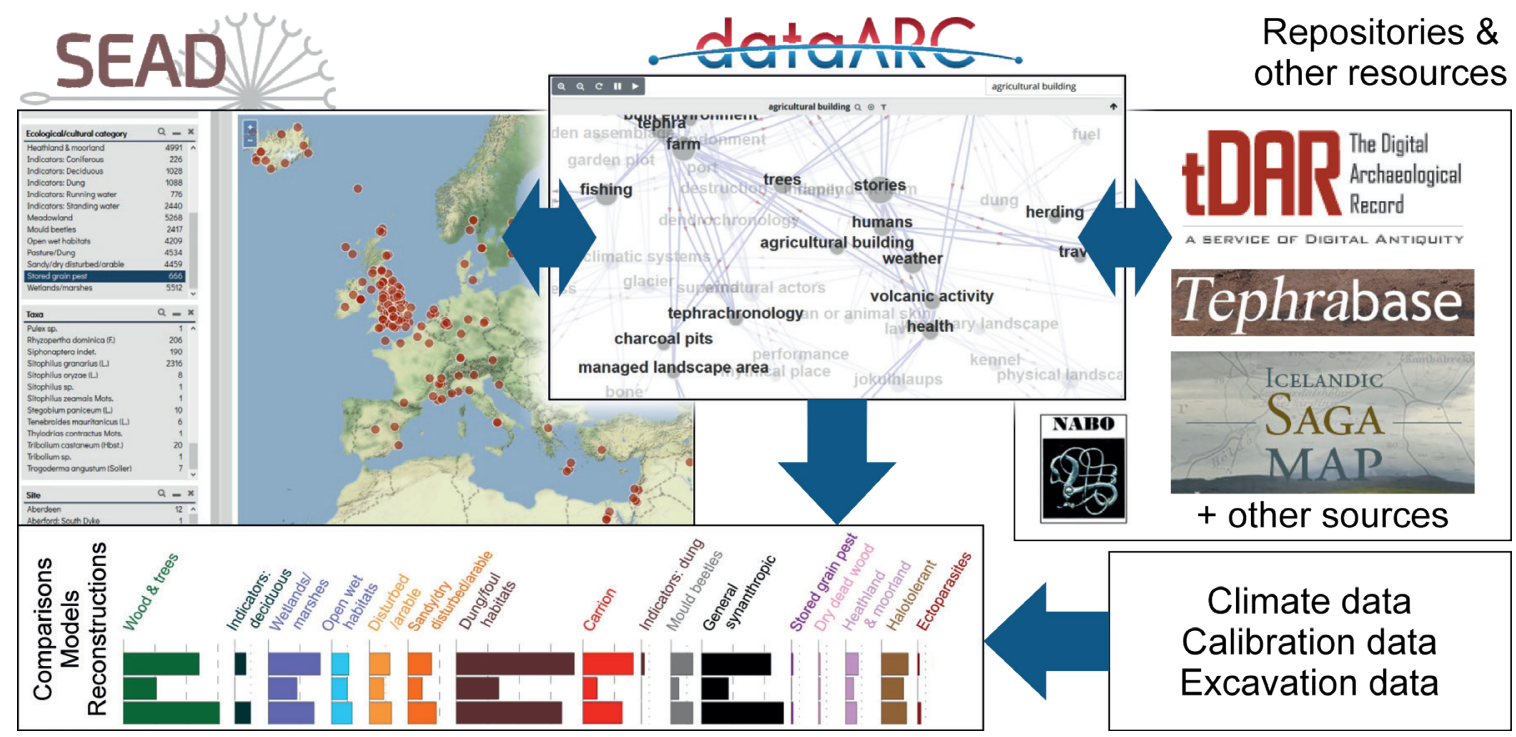

Figure 1: Data-driven research process using archaeological resources. Stored grain pest or parasite occurrences are extracted from SEAD; further information linked through 'agricultural buildings' is extracted from sources identified using DataArc's concept map; the results are visualized as environmental changes across a series of samples. 


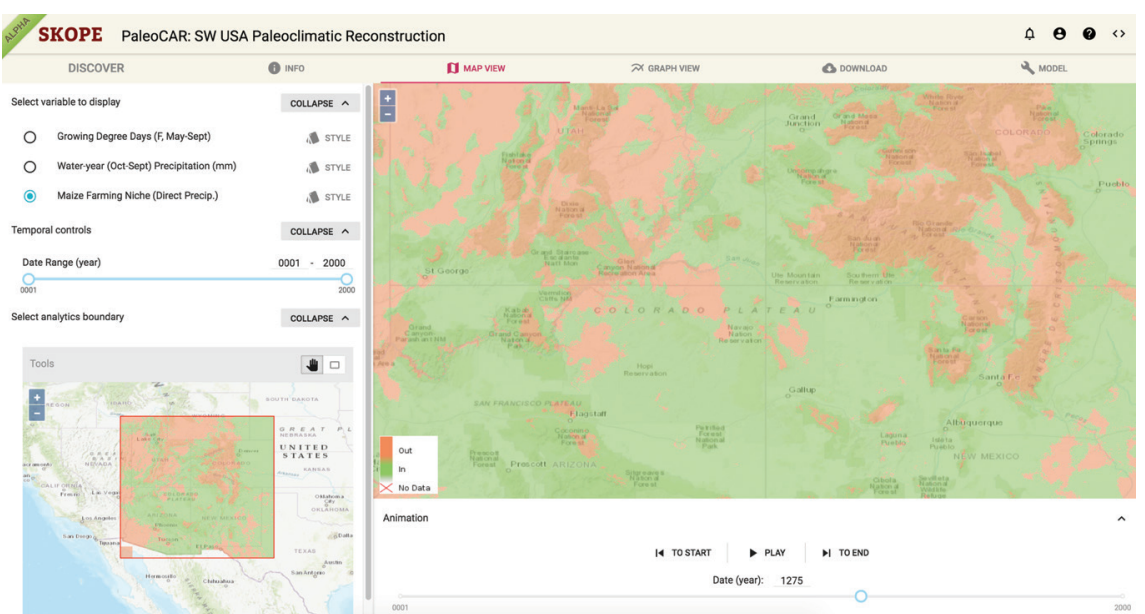

Figure 2: The SKOPE tool depicting a PaleoCAR maize-farming-niche reconstruction. Users can specify region of interest, generate time-series graphs, and download data. Future functionality will include calculating summary statistics and smoothing the time series.

data-integration framework (Kintigh et al. 2018), facilitate such processes.

\section{Archaeological services emphasizing paleoenvironmental data}

Several new projects move beyond the scope of most archaeological archives to provide data and tools for exploring the relationships between archaeological and environmental data. The Strategic Environmental Archaeology Database (SEAD: sead.se; Buckland 2014; Uhen et al., this issue) is specifically designed to provide researchlevel open access to proxy environmental data. These include Quaternary fossil insects, plants, bones, soil parameters, dendrochronology, and geochemistry from mainly European archaeological research (currently, some 15,000 datasets). SEAD includes species traits and cultural/environmental classifications that allow searches for and reconstructions of inferred environments or activities and past species distributions. It provides data to Neotoma and the Earth Life Consortium (see this issue) and archaeological data portals including DataARC (data-arc.org). SEAD facilitates multi-proxy approaches, such as tracking the spread of pests and parasites with people, agriculture and climate change (Fig. 1; Panagiotakopulu and Buckland 2017).

DataARC is designed to go beyond multiproxy databases and suggest innovative links among resources. Essentially an advanced data-discovery tool, currently focused on the North Atlantic region, DataARC links diverse data types through space, time and concept - the latter using a semantic map to interlink higher-level concepts represented by different data or derived products. The suggested linkages not only expose data to users outside of core domains, but also promote novel research using less-obvious interdisciplinary relationships (Fig. 1). Thus DataARC goes further than past traditional archived data-retrieval platforms and federated systems, such as Ariadne, by providing more-advanced exploratory data-analysis tools to an expanded audience.

SKOPE (Synthesizing Knowledge of Past Environments; openskope.org) is designed to provide easy access to paleoenvironmental and paleoclimatic data that have been processed to be readily useful. Some of these datasets have been previously published; others are created through SKOPE. SKOPE focuses on delivering annual, gridded (raster) reconstructions centered on the US Southwest, including:

- High-frequency temperature, precipitation, and maize-farming niche over the last 2000 years, reconstructed for the US Southwest from networks of tree-ring chronologies using the "PaleoCAR" method (Bocinsky and Kohler 2014) (Fig. 2);

- High-frequency Palmer Modified Drought Index over the last 2000 years, reconstructed from tree rings and available as the North American Drought Atlas;

- Elevation data from the Shuttle Radar Topography Mission (SRTM) dataset, available from NASA;

- Contemporary, monthly temperature and precipitation data for the contiguous United States, available from the PRISM Climate Group at Oregon State University.

We plan to add other existing and novel datasets in coming months, including:

- Low-frequency temperature reconstructed from a network of pollen samples available in Neotoma Paleoecology Database (neotomadb.org) using the modern analog technique (MAT; Overpeck et al. 1985), extending to the early Holocene;

- A new temperature reconstruction integrating the high-frequency signal from tree rings with the low-frequency signal from pollen (MAT) through wavelet modulation for Common Era;

- Past species and vegetation community distributions based on the temperature and precipitation fields available in SKOPE;

- Contemporary potential maize productivity fields for several Native American maize landraces.

We are interested in including other legacy paleoenvironmental data that would benefit from the enhanced access and analysis provided by SKOPE.

\section{Conclusions}

Archaeological data processed to reveal socio-ecological interactions are essential to understanding past human experience and how today's world was shaped. Archaeological data that inform on paleoclimates or paleoenvironments are more available than many Quaternary scientists likely realize. The projects we describe enhance access to and facilitate use of paleoenvironmental and archaeological data. The authors welcome further collaboration with paleoclimatologists and paleoecologists to address human and climate interactions more comprehensively.

\section{ACKNOWLEDGEMENTS}

This material is based in part upon work supported by the US NSF: DataArc, 1637076 and 1439389; Digital Antiquity/tDAR, BCS 17-24713, BCS 1153115, and IIS 0624341; and SKOPE, currently, SMA 1637189 (ASU), SMA 1637155 (UIUC), and SMA 1637171 (WSU) and previously, SMA 1439591 (ASU), SMA 1439603 (UCSD) and SMA 1439516 (WSU). SEAD has been supported by the Swedish Research Council (2007-7494 and 20105976), the Swedish Foundation for Humanities and Social Sciences (IN15-0231:1) and Umeå University.

\section{AFFILIATIONS}

'Department of Anthropology, Washington State University, Pullman, USA

${ }^{2}$ Santa Fe Institute, USA

${ }^{3}$ Crow Canyon Archaeological Center, Cortez, USA ${ }^{4}$ Department of Historical, Philosophical and Religious Studies, Umeå University, Sweden

${ }^{5}$ School of Human Evolution and Social Change, Arizona State University, Tempe, USA

${ }^{6}$ Montana Climate Office, University of Montana, Missoula, USA

Division of Earth and Ecosystem Sciences, Desert Research Institute, Reno, USA

${ }^{8}$ Center for Digital Antiquity, Arizona State University, Tempe, USA

${ }^{9}$ School of Information Sciences, University of Illinois at Urbana-Champaign, USA

${ }^{10}$ National Center for Supercomputing Applications, University of Illinois at Urbana-Champaign, USA ${ }^{11}$ School of Humanities, University of Glasgow, UK

\section{CONTACT}

Timothy A. Kohler: tako@wsu.edu

\section{REFERENCES}

Bocinsky RK, Kohler TA (2014) Nat Comm 5: 5618 Buckland PI (2014) In: Earl G et al. (eds) Archaeology in the Digital Era, Papers from the 40th Annual Conference of Computer Applications and Quantitative Methods in Archaeology (CAA)

d'Alpoim Guedes JA et al. (2016) PNAS 113: 14483-14491 Hambrecht $\mathrm{G}$ et al. (in press) Quat Int

Hollesen J et al. (2018) Antiquity 92: 573-586 Jackson RC et al. (2018) Glo Env Ch 52: 58-65 Kintigh KW et al. (2014) Am Antiq 79: 5-24 Kintigh KW et al. (2018) Adv Arch Prac 6: 30-41

Lartet É (1861) Nouvelles Recherches sur la Coexistence de l'Homme et des Grands Mammifères Fossiles Réputés Caractéristiques de la Dernière Période Géologique. Ann Sci nat 4e série, t. XV: 177-253

Li J et al. (2014) Quat Sci Rev 99: 112-121

Lubbock J (1890) [1971] Pre-Historic Times as Illustrated by Ancient Remains and the Manners and Customs of Modern Savages. 5th edition. Books for Libraries Press, $640 \mathrm{pp}$

Overpeck JT et al. (1985) Quat Res 23: 87-108

Panagiotakopulu E, Buckland PC (2017) Quat Sci Rev 156: 23-35

Smith BD, Zeder MA (2013) Anthrop 4: 8-13

Wells JJ et al. (2014) Lit Ling Comp 29: 349-360 